\title{
Developing a Method for Assessing National Demand-Response Transit Level of Service
}

\author{
Ranjit Prasad Godavarthy, Jeremy Mattson, Del Peterson, and Jill Hough \\ North Dakota State University
}

\begin{abstract}
Demand-response transit service is a major source of mobility for older adults and people with disabilities in both urban and rural areas in United States. Federal Transit Administration (FTA) grant programs under sections 5307, 5310, and 5311 all have components designed to increase the availability of paratransit or demand-response transit service. However, there is little information in the National Transit Database (NTD) or elsewhere about the extent of demand-response transit service coverage across the country. The lack of data makes it a challenge to identify gaps in service and unmet needs. The primary objective of this study was to fill the data gaps to the available NTD database to effectively determine the demand-response transit level of service. This study also developed a priority ranking procedure to identify where the greatest needs for service improvements exist in a state.
\end{abstract}

Keywords: Demand-response transit level of service, DRT, LOS, public transportation, demand-response transportation coverage

\section{Introduction}

Demand-response transit (DRT) service is a major source of mobility for older adults and persons with low-income or disabilities in urban and rural areas. DRT also is known by terms such as dial-a-ride, demand-activated transportation, shared-ride paratransit, and flexible-route service. Americans with Disabilities Act (ADA) paratransit is a type of DRT provided for people with disabilities who cannot use a fixed-route service. In general, DRT may serve the general public or certain rider groups such as older adults, persons with a disability, transportation-disadvantaged persons, etc. (KFH 2008).

Federal Transit Administration (FTA) grant programs under sections 5307, 5310, and 5311 have components designed to increase the availability of paratransit or DRT service. In many rural areas, DRT is the only form of transit available, whereas urban areas rely on DRT to complement fixed-route services. Although DRT is a critical 
component of a community's transit system, the data needed to assess the level of service being provided are lacking.

The general transit feed specification (GTFS) has proven to be very useful for allowing public transit agencies to share service information such as locations of stops and routes, schedules, stop times, headways, etc., making it easier to identify and evaluate the level of service being provided. However, the information in GTFS is specific to fixed-route service, and a different method needs to be developed to allow for transit agencies nationwide to share key information about their DRT level of service.

The National Transit Database (NTD) is a standard reporting system for urban and rural transit providers and can be used to assess transit system performance. However, there is little information in the NTD or elsewhere about the extent of DRT coverage across the U.S., which creates challenges in identifying gaps in service coverage and understanding unmet needs. Transit agencies, metropolitan planning organizations (MPOs), and state departments of transportation (DOTs) planning for DRT service often lack data on where the greatest needs for additional service coverage exist. Therefore, there is a great need to fill the data gaps to the available NTD database to effectively assess DRT level of service. The different types of DRT services that were considered in this study include general public DRT, limited eligibility DRT, ADA paratransit, and human service transportation.

The general objective of this study was to develop a method for assessing national DRT level of service. Specific objectives were to determine data needs, design a survey tool for collecting the necessary data, design a framework for identifying DRT service coverage and level of service, test the survey method and framework in selected test states, provide recommendations for deploying a nationwide survey tool, and develop a method for identifying unmet needs and prioritizing service investments.

\section{Framework of the Study}

The framework for evaluating level of service (LOS) for DRT was adapted from the second and third editions of the Transit Capacity and Quality of Service Manual (TCQSM) (Kittelson \& Associates, Inc. 2003, 2013). This framework was then tested in two pilot states-North Dakota and Florida - chosen because they provide a mix of geographic types. North Dakota is largely rural with some small urban areas; Florida has large urban and suburban areas, along with smaller urban and rural areas. Testing the framework in areas with a mix of geographic types could ensure that the effort would be successful if applied nationwide.

The TCQSM defines the level of service for DRT service based on various parameters such as response time, service span, reliability, on-time performance, trips not served, and travel time of demand-response transit (Kittelson \& Associates, Inc. 2003). Service span measures the days per week and hours per day that service is available in a particular area and is a key measure of service availability and quality of service. This study uses service span as a key part of the method for identifying DRT LOS, adopting the framework shown in Table 1. 
TABLE 1.

LOS Measures for DRT Service Based on Service Span

\begin{tabular}{|l|c|c|c|c|c|c|c|}
\hline Hours per Day & \multicolumn{7}{|c|}{ Days per Week } \\
\hline & $6-7$ & 5 & $3-4$ & 2 & 1 & $0.5^{*}$ & $<0.5$ \\
\hline$\geq 16.0$ & LOS 1 & LOS 2 & LOS 4 & LOS 5 & LOS 6 & LOS 7 & LOS 8 \\
\hline $12.0-15.9$ & LOS 2 & LOS 3 & LOS 4 & LOS 5 & LOS 6 & LOS 7 & LOS 8 \\
\hline $9.0-11.9$ & LOS 3 & LOS 4 & LOS 4 & LOS 6 & LOS 6 & LOS 7 & LOS 8 \\
\hline $5.0-8.9$ & LOS 5 & LOS 5 & LOS 5 & LOS 6 & LOS 7 & LOS 7 & LOS 8 \\
\hline$<5^{* *}$ & LOS 6 & LOS 6 & LOS 6 & LOS 7 & LOS 7 & LOS 8 & LOS 8 \\
\hline
\end{tabular}

*Service twice per month.

** The second edition of the TCQSM uses "< 4 hours" as the lowest level for hours of service, but this was revised to " $<5$ hours" in the third edition, which is what is used in this study. The third edition of the TCQSM no longer combines days and hours of service into a single level of service measure.

Source: TCQSM, $2^{\text {nd }}$ Edition; TCQSM, $3^{\text {rd }}$ Edition

The framework shown in Table 1 was adapted from the second edition of the TCQSM with minor modification for the lowest level for hours of service per day, which was implemented from the third edition. Although the third edition no longer combines days and hours of service, this procedure was found to be useful for quantifying service span with a single measure. Based on the number of days and number of hours per each day the DRT service is provided, Table 1 can be used to determine the LOS of the DRT service in that geographic location. A lower number indicates a higher level of service, with LOS 1 being the highest level of service. Further, the method calls for service span data to be integrated with service location to better understand the DRT service coverage. The DRT LOS data then can be mapped to show areas with higher or lower levels of service. Mapping the DRT LOS for each transit agency in a state can provide valuable information regarding service area and LOS throughout the state, and these maps could be used to better understand where service improvements are necessary.

\section{Data Availability and Data Needs}

Although there have been many studies and reports documenting various measures to determine the performance of a DRT service (KFH Group et al. 2008, GAO 2012, Kittelson \& Associates et al. 2003, Ellis 2009, Godavarthy et al. 2014), few studies are available to determine the extent of demand-response service coverage in United States due to the lack of primary data needed for its calculations in the NTD. Key variables for identifying the level of DRT service across the U.S. include geographic coverage, days of service per week, hours of service per day, advance reservation requirements, and service eligibility, data that largely are missing from the NTD. Service span and geographic coverage are two variables that are especially important but have limited data availability. Although the NTD has data for service days and hours for some transit agencies, service span data for DRT service are not available for any agency in the rural NTD.

With regard to geographic coverage data, very general service area (city, or counties served) information is available for some transit agencies in the NTD, but the data available are not specific or precise and, therefore, are inadequate for the study methodology. In the rural NTD, agencies are asked to identify the county or counties in which they provide service. Some of the multi-county providers do not list all of their 
counties, so the data are incomplete. The data also are imprecise because an agency might not provide service within some areas of the county, or the level of service provided may differ within the county. Some areas might receive daily service, and others have service twice per week. Geographic coverage and level of service information at a level finer than county would be helpful. This level of information is not available through the NTD. More detail regarding ADA paratransit service areas also would be useful. ADA paratransit providers may offer service within three quarters of a mile of fixed-route service, as required, or they may provide service to a larger geographic area.

Further, the availability of additional service data for DRT agencies such as minimum advance reservation time, eligibility for using demand-response service and/or ADA paratransit service, and type of DRT service provided (curb-to-curb, door-to-door, etc.) would be helpful for identifying the type and level of service being provided. These data also are not available from the NTD. A significant limitation of the NTD is that it does not distinguish ADA paratransit from general public DRT and other forms of demandresponse services.

\section{Developing a Survey Tool for Gathering Data Needed for Determining DRT LOS}

Based on the study framework and the analysis of NTD data, there is need for additional service details from transit agencies providing DRT service in the United States. As the long-term vision from this project likely would be to expand and understand the level of service coverage of DRT service nationwide, uniform, complete, and accurate data would be needed from the NTD or another data source. To collect the necessary data, a new survey tool needed to be developed that could be administered nationwide. To that end, this study developed two versions of a survey tool and tested them with transit agencies in North Dakota and Florida.

\section{North Dakota Study}

An online survey tool was prepared by the research team and distributed in August 2014 to all transit agencies providing DRT service in North Dakota. The intent of the survey was to gather information on service eligibility, service span, service area, service type, minimum advance reservation time, and trips turned down. A map tool was developed and used in the survey to collect information regarding service area and span of service. The reason for using a map tool was that it may be easier and quicker for transit agencies to identify and select their service areas on a map than to provide this information in some other way. Census tracts were used as clickable areas to provide service span and other details.

The survey was distributed to 33 transit agencies in North Dakota identified by the North Dakota Department of Transportation (NDDOT). Responses were received from 27 agencies, yielding a response rate of $82 \%$. The high response rate was due to the fact that NDDOT requested transit agencies to complete the survey. The DRT service details for the transit agencies that did not respond to the survey were obtained from the agency's website, and the results were summarized to be used for calculating the level of service values. 
Most transit agencies in North Dakota (23 out of 27) provide DRT service for the general public, one provides limited-eligibility DRT service for older adults, and the remainder provide ADA paratransit. Transit agencies operating DRT services commonly require reservations to be made 24 hours in advance or during the previous service day, but more than half allow reservations to be made the same day as the trip, including nine agencies that provide trips within 30 minutes of making the reservation. More details about the survey questions, detailed survey responses, and other data can be found in the final report of the study (Godavarthy et al. 2015).

Using the number of days DRT service was provided and number of hours of service per day, the level of service in the census tract areas was calculated using the methodology described in Table 1. Based on this framework, the LOS for all types of DRT services was calculated and mapped across the state (Figure 1). Results show that DRT LOS was highest in the urban areas of Fargo, Bismarck, and Grand Forks and indicate that the lowest levels were in the north central parts of the state and some eastern counties.

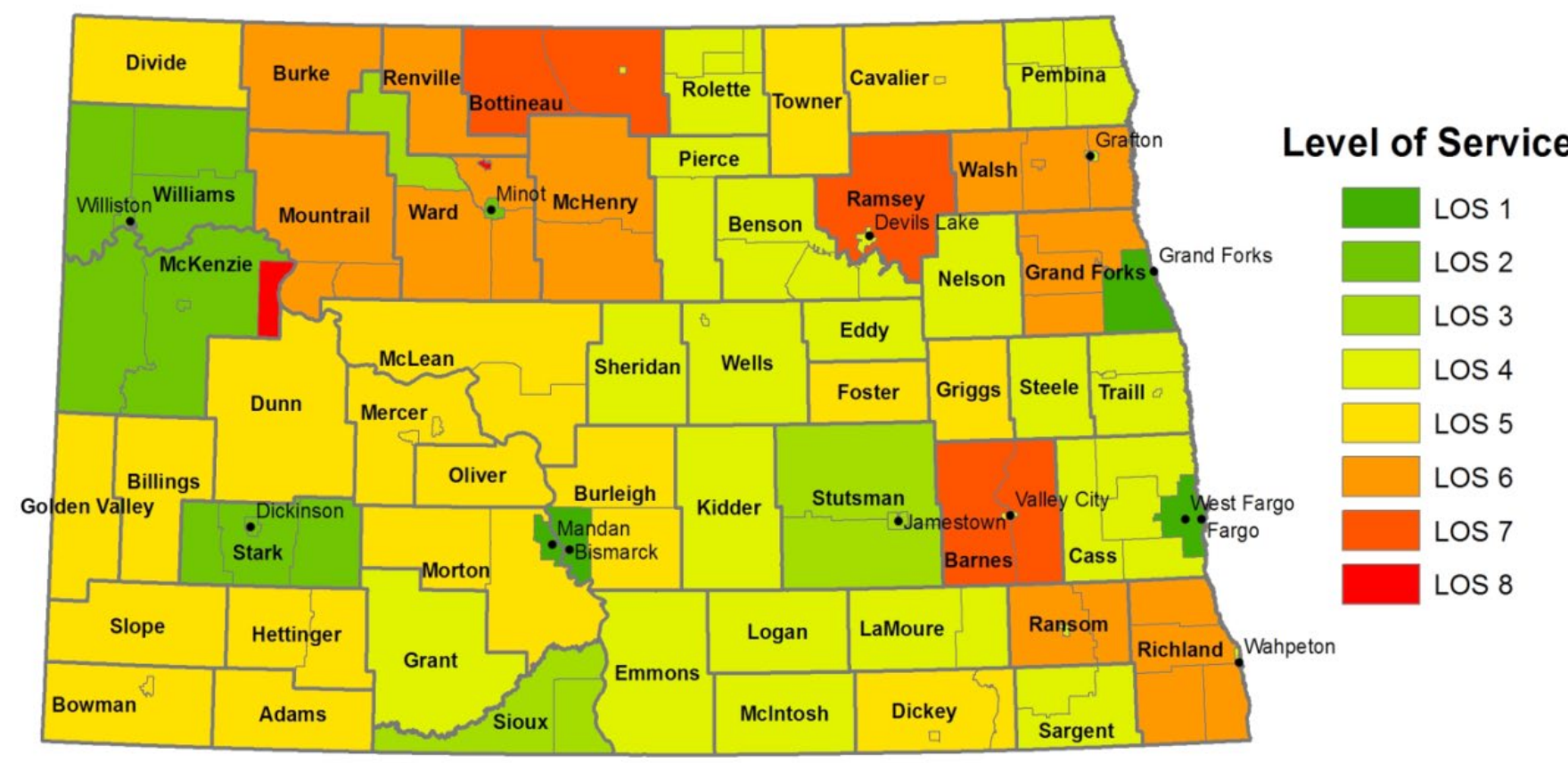

FIGURE 1. DRT level of service in North Dakota, all types of services

Most respondents did not have a problem using the map and selecting the regions with DRT service. However, an issue identified was that sometimes small census tracts were missed (not selected in the map tool) by the survey respondents-some towns have their own census tract, with the rest of the county divided into one or more larger tracts, and the respondents did not see the smaller tract. For this reasons, the research team decided to use a different approach for the Florida survey. 


\section{Florida Study}

An online survey tool was prepared by the research team using Qualtrics software and was distributed in February 2015 to all transit agencies providing DRT service in Florida. Similar to the survey conducted in North Dakota, this Florida survey gathered details about service eligibility, service span, service area, service type, and minimum advance reservation time. However, the approach for determining the geographic location of the service provided was different from that used in the North Dakota survey.

Instead of using a map to identify service areas, respondents were asked to identify counties and cities in which their agency provides service and the days and hours of service in each. Respondents were first asked to identify counties in which their agency provides DRT service; then, for the individual county or counties selected, they were asked if the agency provides the same days and hours of service throughout the county, or different levels of service, or does not serve some areas. If service was the same throughout the county, agencies were asked to identify the number of days and hours of service provided. If service differed, respondents were asked to identify the number of days and hours of service for each from a list of cities in the county, and. Rural areas of a county not belonging to any city also were included and referred to as "other rural areas."

The survey was distributed to Florida DRT agencies via Florida Community Transportation Coordinators (CTCs), the Florida RTAP listserv, and contacts from the Florida Public Transportation Association. Transit agencies identified in the NTD were contacted by email individually if they did not respond. From 56 transit agencies identified in Florida according to the NTD, responses were received from 48 agencies (86\%) providing some kind of DRT service - 38 from the NTD list, 7 whose service details were gathered from their website or via phone conversation, and 3 that were not on the NTD list. Since this study aimed toward gathering service details for all counties in the state, a response closer to $100 \%$ would have been more useful.

More than $50 \%$ of the responding transit agencies in Florida provide traditional-fixed route transit service. DRT service for the general public was provided by 22 responding agencies, and ADA complementary paratransit service was provided by 27 agencies. Most agencies (25) operating DRT services required reservations to be made 24 hours in advance or during the previous service day; a few providers (9) required reservations 48 hours in advance.

Since the Florida survey was not conducted using a map, mapping the resulting service data required a few extra steps. Using census tracts for mapping is desirable because of the availability of tract-level population and demographic data from the American Community Survey (ACS). Census tracts also provide greater detail than simple countylevel data. To map the Florida level of service data, census tracts were assigned either to a city or, if the tract was completely outside a city, to the "other rural areas" for its county. Using ArcGIS, census tracts were dissolved together to create 450 geographic areas for the state, representing individual cities and one rural area for each county. These 450 geographic areas matched the areas included in the survey. 
Using the number of days of DRT service and hours of service per day, the level of DRT service for the areas in Florida was calculated using the methodology described in Table 1. Figure 2 shows the LOS for all types of DRT services in Florida, except for a few counties for which data were not available.

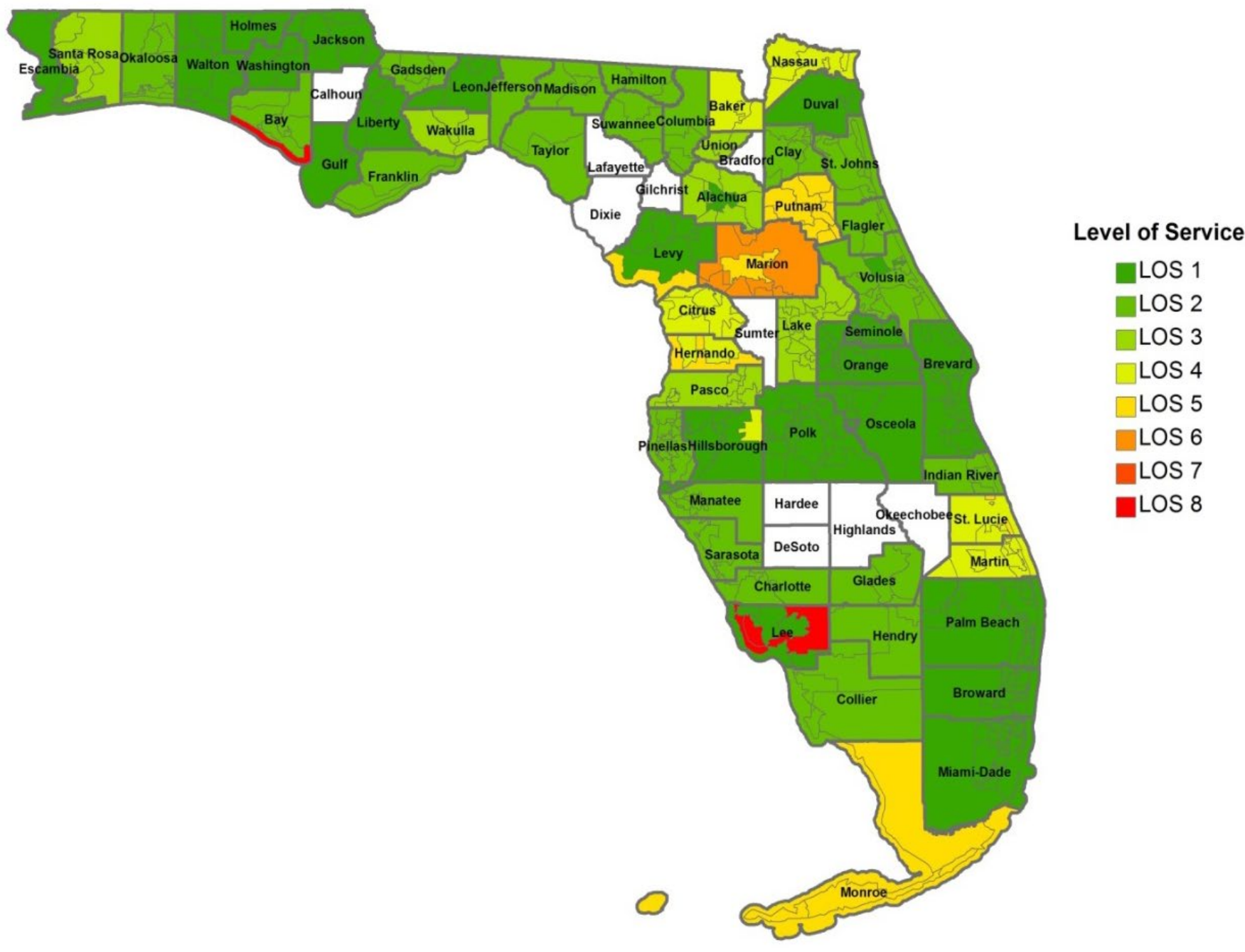

FIGURE 2. DRT LOS in Florida, all types of services

Similarly, Figure 3 shows the level of DRT service available to the general public in Florida. Because Florida has a number of fixed-route transit systems, many DRT services consist of ADA paratransit, which is not available to the general public. This differs from North Dakota, where most DRT service is available to the general public. 


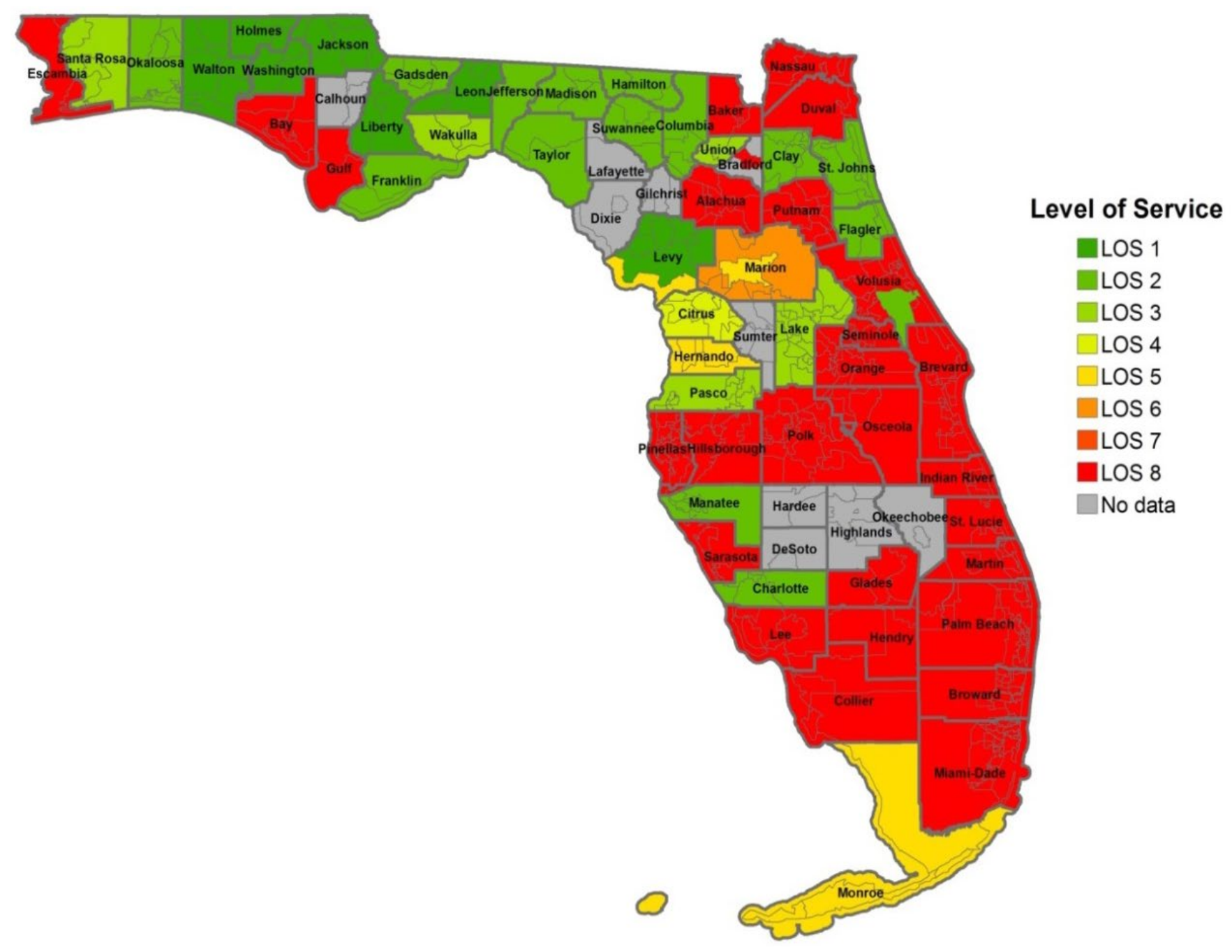

FIGURE 3. DRT LOS in Florida, general public services

Most Florida agencies found the survey "very easy" or "easy" to complete and without a significant time commitment. Only two agencies responded that the survey was "somewhat difficult" to complete, and none indicated that it was "difficult" or "very difficult." Most agencies completed the survey within 5-15 minutes, and many completed it within 10 minutes.

By replacing the map tool used in the North Dakota survey with a set of simple questions, it was easier for the transit agencies to provide the necessary information. Furthermore, the data collected from the Florida survey were more detailed, as they included specific information for every city in the state and were of a higher quality. The method used in the Florida survey left fewer possibilities for data collection error. The only drawback from the survey was that mapping the survey data and comparing those results to ACS population data required a few additional steps, as discussed above. 


\section{Priority Ranking for DRT Service Improvements}

The LOS values and service coverage data derived above provided valuable information about the extent of DRT service, but these measures did not completely identify if the mobility needs of transit-dependent populations were being met, nor did they identify the areas with the greatest needs for service improvements. There should be a sound procedure to understand the populations that are dependent on DRT service and if enough service is being provided. Also, there is a need for understanding which locations have greater needs for new or improved service. Such assessments can be made by comparing LOS data with population and demographic data. The study focused on analyzing the transit needs of target markets who would be using some type of a DRT service (including ADA paratransit) and who are transit-dependent.

Previous research by Mielke et al. (2005) and Mattson and Hough (2015) developed a mobility needs index to identify counties in North Dakota with the greatest need for mobility services. This study used the previously-developed model and applied it to areas in North Dakota and Florida. The factors deemed important for determining mobility needs were populations age 65 or older, populations with a disability, and populations below the poverty line-categories of people who would most likely use some type of DRT service.

The index was calculated using the following procedure. First, population densities were calculated for each of these three factors. Census tract level data from the ACS 2009-2013 five-year estimates were used for total populations age 65 or older, total populations with a disability (including all age groups), and total populations with income at $100 \%$ or below poverty. Second, the geographic areas were ranked from highest to lowest population densities and grouped into five equally-sized classes, using quintile values, for each of the three factors. Geographic areas in the lowest $20 \%$ were given a value equal to 1 , the next $20 \%$ were given a value equal to 2 , and so on, and the highest $20 \%$ were given a value of 5 . In the last step, the three values were averaged for each geographic area to produce its mobility needs index. The process thus ranked all regions on a scale of 1 to 5 , with higher values identifying areas with greater mobility needs. Although the procedure did not directly measure need, the measure could be used as a proxy for need.

The resulting mobility needs indices for North Dakota and Florida are mapped in Figures 4 and 5. As noted by Mielke et al. (2005), this methodology is only an attempt to measure needs associated with identifiable demographic groups; the measurement does not suggest that all needs are unmet. To the contrary, some cities may have systems and services in place that satisfy many residents' mobility needs. 


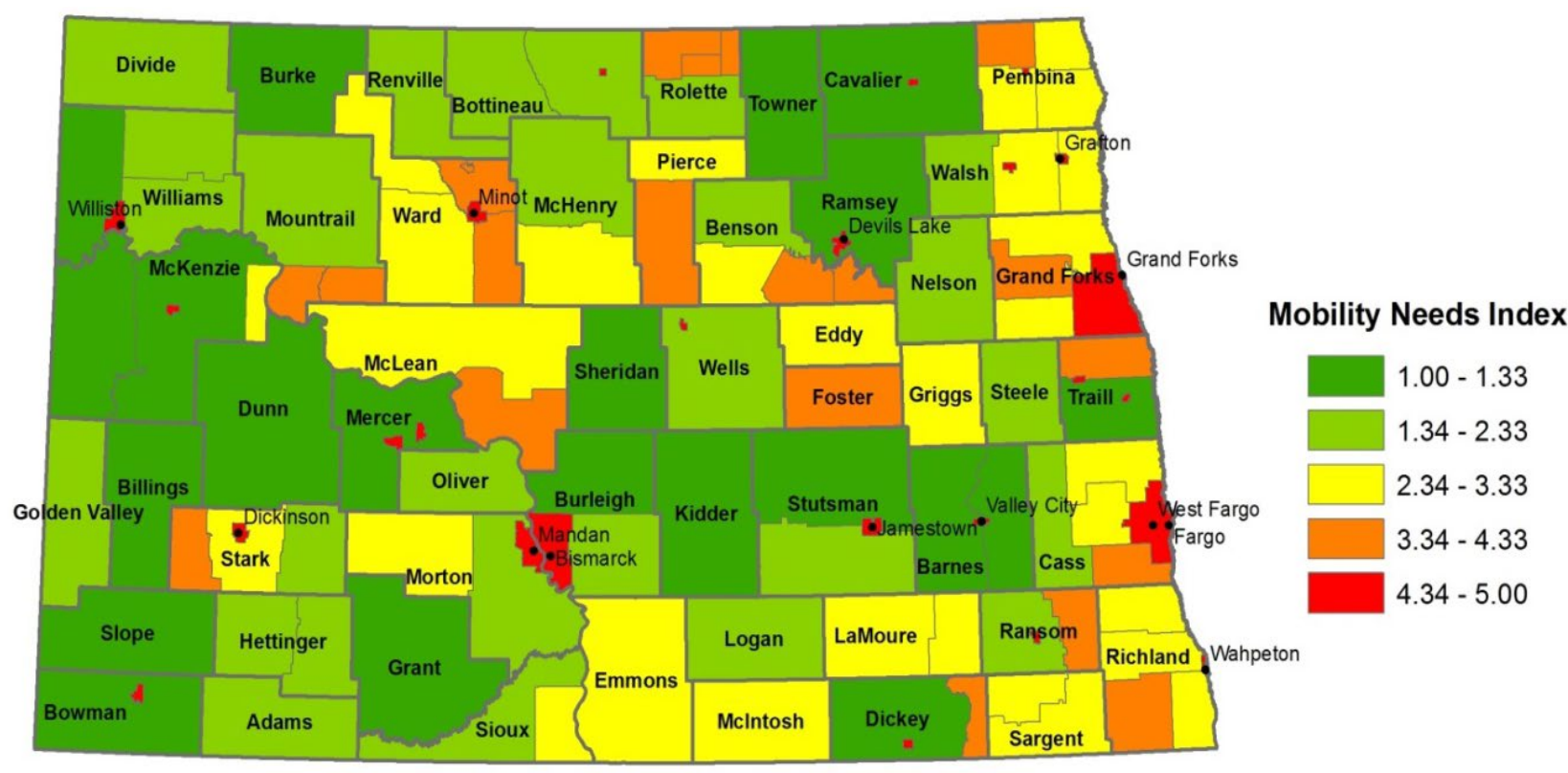

FIGURE 4. Mobility needs index for North Dakota

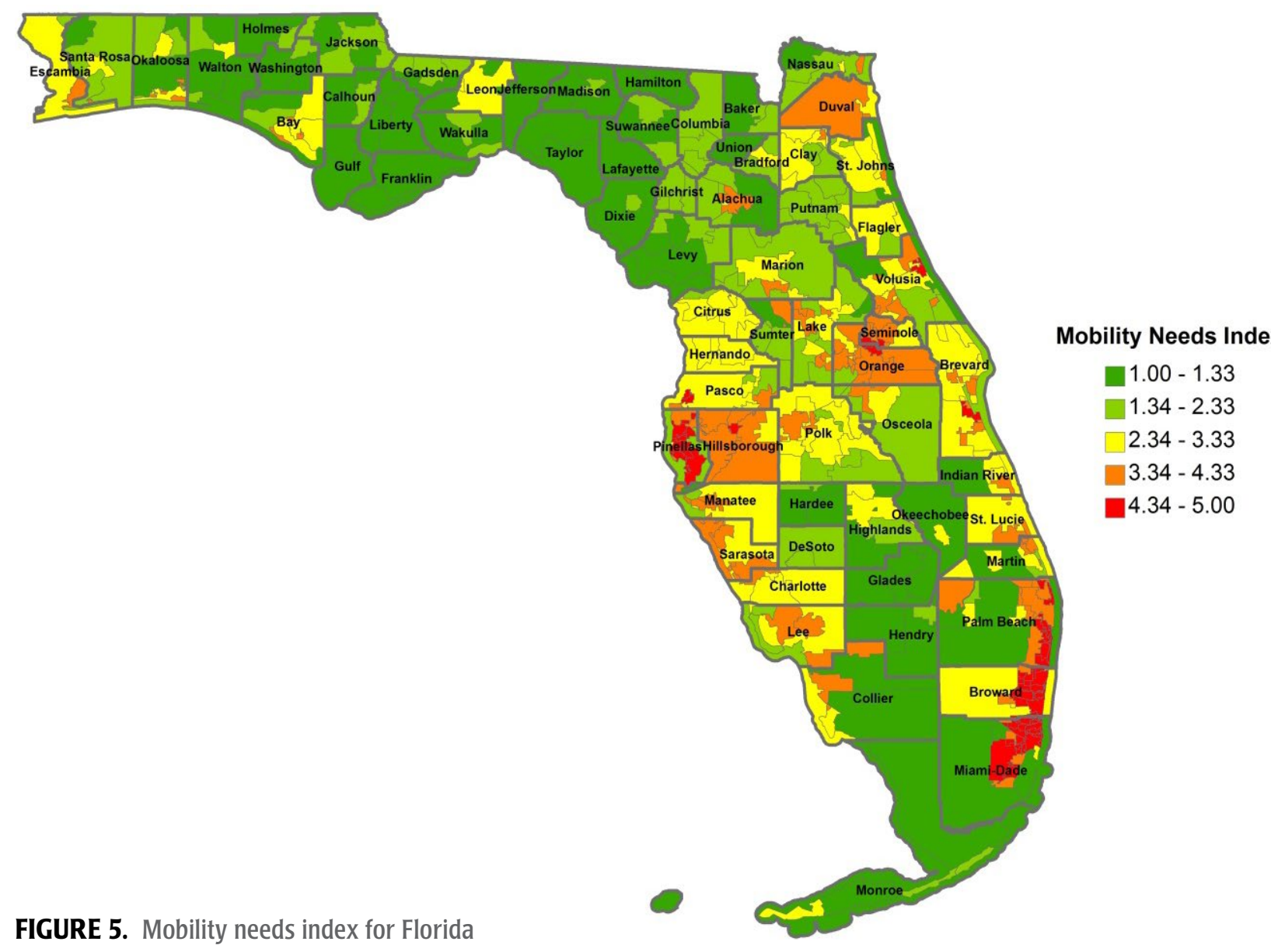




\section{Identifying Priorities for Service Improvements}

Comparing the mobility needs index with the existing LOS provides information about where the greatest needs exist for service improvements. This study developed a method of combining these two sources of information to rank areas in terms of needed improvements. This information can help transit agencies, MPOs, and state DOTs in making investment decisions by planning or improving DRT service.

The priority rank incorporates two factors: the mobility needs index and the existing LOS, as calculated in previous sections. Combining these two data sources, a matrix was created to prioritize needed service improvements, as shown in Table 2 . To determine the priority rank for an area, the level of DRT service available was first determined. Then, from the LOS columns in Table 2, the mobility needs index for the area was determined to find the priority rank. A scale of $1-10$ was used, with 1 indicating the greatest need for service improvements and 10 indicating the least need.

TABLE 2.

Priority Ranking Measure for DRT Service Improvements

\begin{tabular}{|l|c|c|c|c|c|c|c|c|}
\hline $\begin{array}{c}\text { Mobility } \\
\text { Needs Index }\end{array}$ & LOS 8 & LOS 7 & LOS 6 & LOS 5 & LOS 4 & LOS 3 & LOS 2 & LOS 1 \\
\hline $5-4.34$ & 1 & 1 & 2 & 2 & 4 & 7 & 7 & 8 \\
\hline $4.33-3.34$ & 1 & 2 & 2 & 5 & 5 & 8 & 8 & 9 \\
\hline $3.33-2.34$ & 2 & 2 & 4 & 5 & 6 & 9 & 9 & 9 \\
\hline $2.33-1.34$ & 3 & 3 & 5 & 6 & 8 & 9 & 9 & 10 \\
\hline $1.33-1.00$ & 4 & 4 & 6 & 8 & 9 & 10 & 10 & 10 \\
\hline
\end{tabular}

Areas with a high population density (and, therefore, a high mobility needs index) and a low level of service have the highest priority for service improvements; those with a low population density (and low mobility needs index) and a high level of service have little or no need for service improvements. As the table shows, areas with a higher mobility needs index or lower level of service have greater priority for improvements. However, identifying priorities is subjective; the table provides one possible method for prioritizing needs, but different transit planners and decision-makers may have their own preferred priority rankings. The point of this exercise was to demonstrate how the LOS data collected in this study could be combined with ACS data to identify areas with the greatest needs for DRT service improvements.

Using the mobility needs index values and LOS values of DRT service for all the geographic regions and following the procedure from Table 2, the priority rankings for all geographic areas in Florida and North Dakota were estimated and mapped (Figures 6 and 7). The Florida priority rankings were calculated based on all DRT services currently available. Areas with higher priority rankings, those ranked 1-5 (shown as red or orange the figures), are the locations where the mobility needs are not being met as well with DRT service and where there should be greater priority for DRT investments. There is a greater variation of priority rankings in North Dakota than in Florida due to a greater variation in current service levels. 


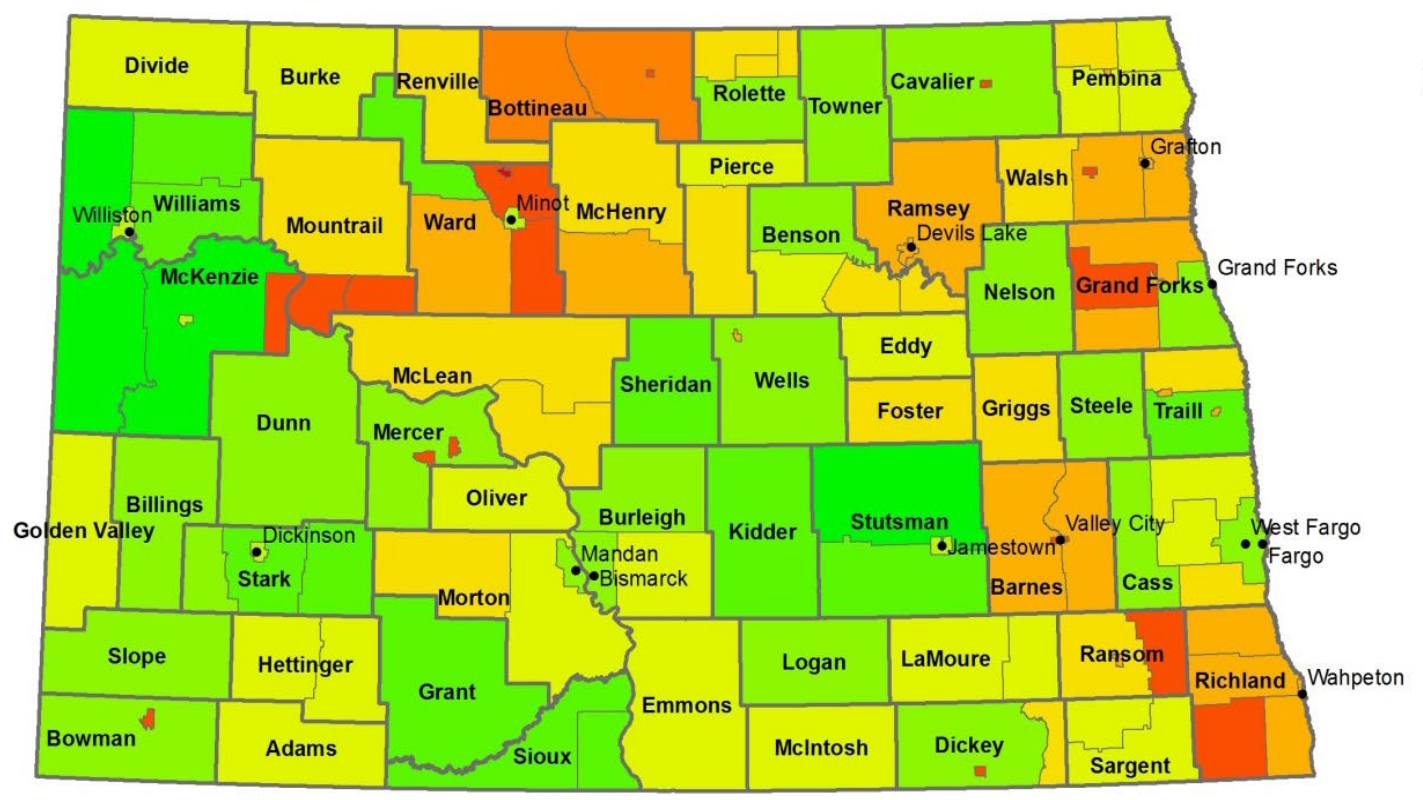

\section{Priority Rank}

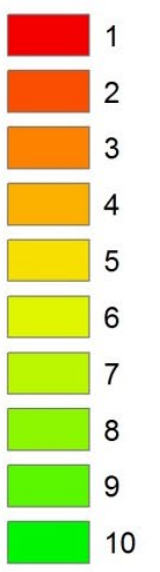

FIGURE 6. Priority ranking for DRT service improvements in North Dakota

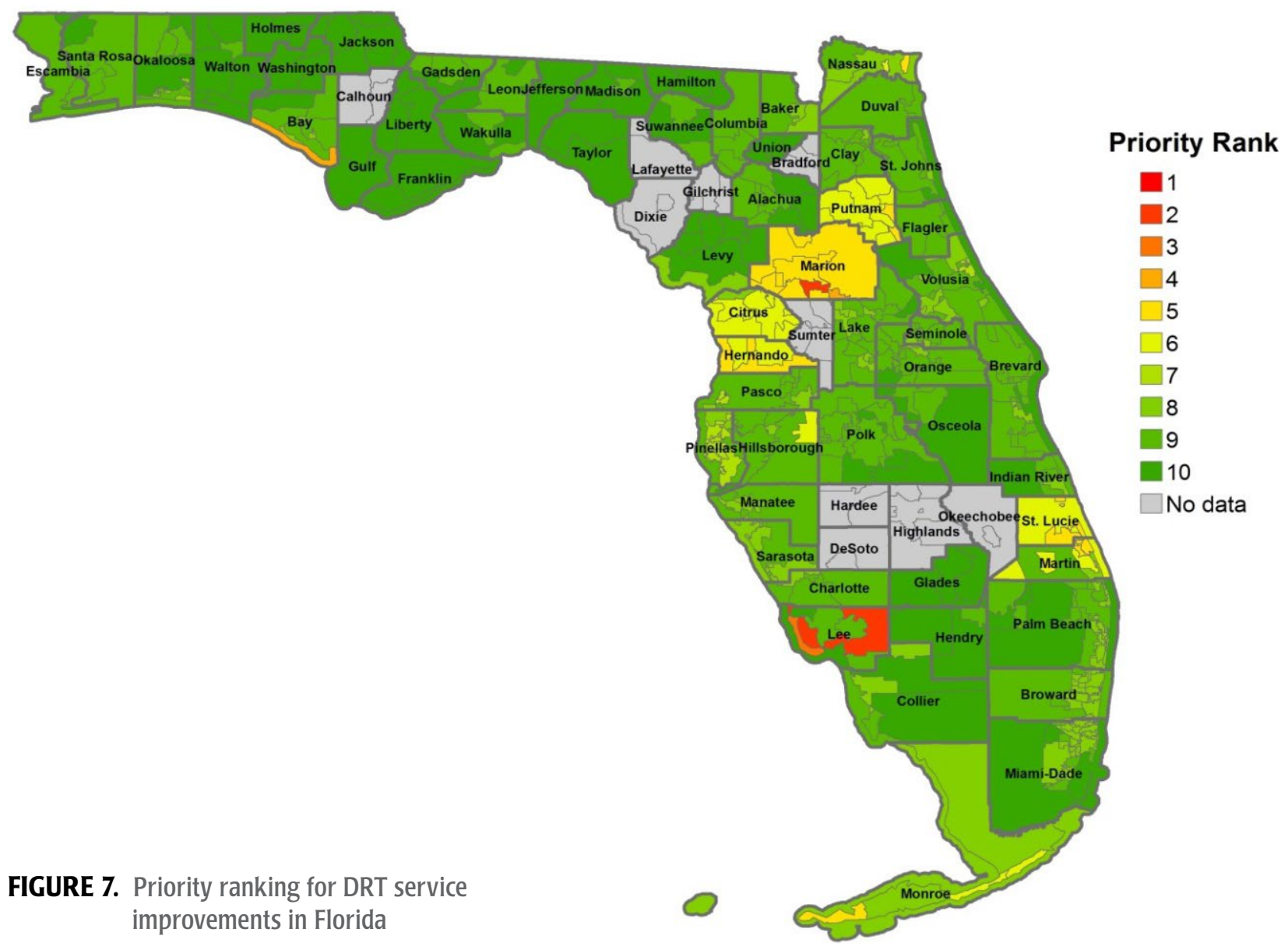


This is one method for prioritizing investment needs that should be considered in conjunction with other sources such as existing NTD data and public input. Other data collected in the survey, such as service type, service eligibility, and minimum advance reservation time, also should be considered when analyzing current services.

\section{Conclusions and Recommendations}

This study attempted to determine the level of service of DRT transit service in North Dakota and Florida. Based on the framework adapted in this study to determine the national DRT level of service, DRT service details such as service span and service area are critical for determining the coverage of DRT service. Therefore, having such data available in the NTD or elsewhere for all U.S. transit agencies operating any type of DRT, including ADA paratransit, would be helpful for understanding the current level of service being provided and identifying areas that should be prioritized for service improvements.

Availability of additional DRT service details such as type of service eligibility, service provided (door-to-door, curb-to-curb, etc.), and minimum advance reservation time would be helpful to better understand DRT quality of service and thereby address transit needs in an effective way. Distinguishing between ADA paratransit, general public DRT, and other forms of DRT also would provide valuable information. Gathering these details from transit agencies would help to better identify the service levels being provided to target markets. This study developed a survey tool to collect these service details from DRT agencies, overcoming current data limitations.

As evidenced by responses from the survey of Florida agencies, the reporting burden for transit agencies to provide this information is minimal. Therefore, this study recommends using the survey instrument for the Florida survey for other states or nationwide. Surveys conducted with transit agencies in North Dakota and Florida did not have a $100 \%$ response rate, but the North Dakota survey had a very high response rate because of assistance from the state DOT. Making responding to the survey mandatory through the NTD or some other data collection method would be needed to achieve $100 \%$ response.

A mobility needs index was developed based on population densities of older adults, people with disabilities, and those living in poverty to identify areas that likely have greater needs for DRT services. This study also developed a priority ranking procedure to understand where the greatest needs for service improvements exist by comparing the mobility needs index values with existing levels of service. This procedure allows transit planners to more easily identify areas with the greatest needs for service improvements. Although this procedure ranked all areas 1-10, the ranking is subjective and could be modified according to priorities in any state.

There are some limitations to the study and areas for future research. Although the survey tool provides a significant improvement in service coverage data, it may not capture all details in service levels. For example, service levels may differ within the same city or within the rural areas of a county, and service boundaries might not follow census tract boundaries. Future research could use a different approach for calculating 
population densities. This study based population density on total area, but basing it on total inhabited land could provide better results. Future research also could consider remote populations as a population of need, because long travel distances also could be a contributing factor to transit needs.

\section{Acknowledgments}

Funds for this study were provided by the U.S. Department of Transportation through the National Center for Transit Research at the Center for Urban Transportation Research, University of South Florida.

\section{References}

Ellis, Elizabeth, and Brian McCollom. 2009. TCRP Report 136: Guidebook for Rural Demand-Response Transportation: Measuring, Assessing, and Improving Performance. Transit Cooperative Research Program, Washington, DC: Transportation Research Board.

GAO. 2012. "ADA Paratransit Services: Demand Has Increased, but Little is Known about Compliance." GAO-13-17, November.

Godavarthy, Ranjit, Jeremy Mattson, and Elvis Ndembe. 2014. "Cost-Benefit Analysis of Rural and Small Urban Transit." University of South Florida, Tampa: National Center for Transit Research, 21177060-NCTR-NDSU03.

Godavarthy, Ranjit, Jeremy Mattson, Patrick Nichols, Del Peterson, and Jill Hough. 2015. "Developing a Method for Assessing National Demand Response Transit Level of Service." University of South Florida, Tampa: National Center for Transit Research, 21177060-NCTR-NDSU06.

KFH Group, Inc., Urbitran Associates, Inc., McCollom Management Consulting, Inc., and Cambridge Systematics, Inc. 2008. TCRP Report 124: Guidebook for Measuring, Assessing, and Improving Performance of Demand-Response Transportation. Transit Cooperative Research Program, Washington, DC: Transportation Research Board.

Kittelson \& Associates, Inc., KFH Group, Inc., Parsons Brinckerhoff Quade \& Douglass, Inc., and Katherine Hunter-Zaworski. 2003. TCRP Report 100: Transit Capacity and Quality of Service Manual, 2nd Edition. Transit Cooperative Research Program, Washington, DC: Transportation Research Board.

Kittelson \& Associates, Inc., Parsons Brinckerhoff, KFH Group, Inc., Texas A\&M Transportation Institute, and ARUP. 2013. TCRP Report 165: Transit Capacity and Quality of Service Manual, Third Edition. Transit Cooperative Research Program, Washington, DC: Transportation Research Board.

Kittelson \& Associates, Inc., Urbitran Associates, Inc., LKC Consulting Services, Inc., MORPACE International, Inc., Queensland University of Technology, and Yuko Nakanishi. 2003. TCRP Report 88: A Guidebook for Developing a Transit 
Performance-Measurement System. Transit Cooperative Research Program, Washington, DC: Transportation Research Board.

Mattson, Jeremy, and Jill Hough, Ph.D. 2015. "Identifying and Satisfying the Mobility Needs of North Dakota's Transit System." Departmental Report No. 280, Upper Great Plains Transportation Institute, North Dakota State University.

Mielke, Jon, Jim Miller, David Ripplinger, Del Peterson, and Jill Hough. 2005. "Personal Mobility in North Dakota: Trends, Gaps, and Recommended Enhancements." Departmental Report No. 165, Upper Great Plains Transportation Institute, North Dakota State University.

\section{About the Authors}

RANJIT GODAVARTHY (ranjit.godavarthy@ndsu.edu) is an associate research fellow at the Upper Great Plains Transportation Institute (UGPTI) at North Dakota State University. He received a Ph.D. in Civil Engineering from Kansas State University. His research interests include transportation and public transportation, highway safety, low volume road (LVR) safety, roundabout studies, pedestrian studies, and freight transportation.

JEREMY MATTSON (jeremy.w.mattson@ndsu.edu) is an associate research fellow at UGPTI. He holds a B.A. in economics and business management and an M.S. in agricultural economics and is currently in the Transportation \& Logistics Ph.D. program at North Dakota State University. His research interests include mobility and transportation needs of older adults and people with disabilities, mobility management, access to health care, rural intercity transportation demand, alternative fuels, travel behavior, and impacts of higher fuel prices.

Del Peterson (del.peterson@ndsu.edu) is an associate research fellow at UGPTI. He holds a B.A. in business management and economics and an M.S. in agribusiness and applied economics with an emphasis in transportation economics. He has conducted research pertaining to the small transit vehicle industry, small urban sprawl, intelligent transportation systems (ITS) deployment, and passenger mobility enhancements using geographic information systems (GIS) and similar technologies.

JILL Hough (jill.hough@ndsu.edu) is the director of UGPTI's Small Urban and Rural Transit Center (SURTC), which focuses on research, education, and training for the public transportation industry. She received her Ph.D. degree in the transportation technology and policy program at the University of California-Davis and holds B.S. and M.S. degrees in agricultural economics from North Dakota State University. Her primary research areas relate to workforce development, livability, mobility of older adults and disadvantaged persons, ITS, and transit planning and management. 